\title{
Assessment of the Effect of Out-of-Stock on Customers Purchasing Behavior
}

\author{
Dawit H. \\ Debre berhan University, College of business and economics, Department of logistics and supply chain \\ management
}

\begin{abstract}
The objective of this exploratory study was to examine stock-outs as an event and document their effects on changes in customer attitudes. A study containing both open-ended and close-ended elements was validated through a pilot study and used to collect data from 100 randomly selected participants spending at Shewa Shopping Center in Addis Ababa. The finding indicated that repeated stock-out experiences reduced customers' loyalty to brand and retailer and caused customers to leave both retailers and brand. Participants indicated that stock-out effects can be shielded through improved inventory management and better customer service. Explicit recommendations involved apology, price discounts and free delivery. The finding of this study will enable retailers to gain deeper considerate of how stock-out affects customers shopping experiences and loyalty, and offer alleviation measures to improve both. In addition, the finding will provide a positive change to both customers and retailers, where shoppers will enjoy pleasant shopping experiences and retailers can maintain their competitive advantage via loyalty of their customer.
\end{abstract}

Keywords: Showa Shopping Center, Stock-out, Shoppers Behavior, Buyers Loyalty

DOI: $10.7176 / \mathrm{EJBM} / 11-1-01$

\section{INTRODUCTION}

\subsection{Backdrop of the study}

Starting from the early 1990s, when organizations began to recognize the dynamics of demand fluctuation, companies have considered inventory management as integral to the supply chain process and have introduced innovative ideas to compete globally. By tradition organizations have held more inventory than required to meet variations in customer request. Musalem and Dekker (2005) proposed, that one of the most vital aspects affecting the supply chain performance is the management of inventories. Majority of customers believe that a retailer's inventory management is the main cause for stockout (Yang et al., 2003). Firms also discovered there were significant costs and risks associated with holding speculative inventory, provoking retailers to seek more efficient management (Goldsby, 2006). Firms are exploring ways to deal with the costly problem of stockout and uncertainty of demand by staging inventory in containers ahead of customer demand (Comez \& Kiessling 2012). Corresponding the exact amount of inventory to meet customer uncertain demand has presented a problem for managers Zinn \& Liu (2008).

Turbulences in the supply chain can have severe effects on firms applying the lean principles Svensson, (2000). Very little inventory could lead to stock-outs; as a consequence, customers could become dissatisfied and take their business elsewhere (Koumanakos, 2008). Too low product availability resulting from using lean inventory causes stock-outs and can lead to decrease in customer loyalty and could cause retailers to increase safety stocks (Bardaki et al 2007).

When a customer encounters stockout, the retailer can lose up to half of the intended purchases (Gruen \& Corsten, 2007). Buyers' responses to stock-out can be expensive to retailers. Blazenko and Vandezande (2003) stated, there are two adverse consequences of stock-outs, immediate foregone profit and long-run loss of revenue arising from the shift of customers to more dependable sources of supply. This study will enable retailers to gain in depth understanding of the stockout problem and use the recommended mitigating measures to minimize the negative effects of stockout on their buyers.

\subsection{Statement of the Problem}

As stock-out experiences negatively affect customers' purchasing behaviors and shopping attitudes retailers using the lean inventory strategy have increased risk of stock-outs and dropping customers Rani \& Velayudhan (2008). Gradually, stock-outs are known as a retail problem by both researchers and practitioners. Vasconcellos \& Sampaio (2009), claim that for as many as $44 \%$ of customers who experience stock-out will go to competitors rather than buy a substitute item at the stores where they typically shop Zinn \& Liu (2008). The general business-related problem is the costly effects of inventory stock-outs on retailers within the lean retailing industry.

The entire cost of dissatisfied customers shift permanently to competitors is considered in terms of lifetime customer income Lam \& Ip (2011). The particular business problem is related to changes in customers' purchasing behaviors and reduction in loyalty to their preferred brand or retailer after experiencing stock-out. 
Huge numbers of customers might abandon their purchases and shift to another retailer because of stock-out (McKinnon et al, 2007). Stock-out experiences have greater implications beyond retailers' profits and can affect profits of stakeholders across the supply chain (Gruen \& Corsten 2007).

\subsection{Objective of the Study}

The objective of this research is to explore the effects of lean inventory practices on customer service to determine and analyze the qualitative relationship between stock-out experiences and changes in shopper purchasing behaviors. Customers who experience stock-out frequently go to a competitor to purchase a desired product, which causes a loss of retailer profits. Janssens \& Ramaekers (2011) find out that stock-outs negatively affect profits in both the short and long run for retailers. The problems related with lean inventory, such as stocking out and the additional expenses from more scheduled deliveries could be causing some retailers to halt using lean practices. Some companies hold additional safety stocks and audits to alleviate the issue of stock-out and demand uncertainty Janssens \& Ramaekers (2011); Nasr et al, (2012). Results of this research will underline to retailer's specific customer and profit-related problems associated with lean practices and identify possible solutions to alleviate the negative effects of stock-out.

\subsection{Research Questions}

Goldsby et al. (2006) claim that the lean principle relies on forecasts rather than demand-driven replenishment. Retailers have used lean inventory as a strategy to minimize costs and maximize efficiency and profits. Having lower inventories on hand coupled with volatile customer demand and ramped up advertising of manufacturers make retailers susceptible to increased risk of running out of certain products.

Generally, this research asked how do stock-out experiences affect customers' purchasing behaviors and loyalty to their preferred brand or retailer. The following sub-questions amplified the central research question:

1. How does stock-out affect customers' brand loyalty shopping behaviors?

2. How does stock-out affect customers' short- and long-term loyalty to retailers?

3. What shall retailers do to alleviate the adverse effects of stock-out on customers?

\subsection{Limitations}

This study focused on customer behaviors after stock-out experiences at Shewa Shopping Center at Addis Ababa. The stock-out experience from the participants was before one week back from the study day. Stock-out events that happened in shopping journeys prior to one week was not considered because the shopping trip memory of the customer might not be clear. Conclusions might reflect about customers of Shewa Shopping Center and not apply across other shopping centers in the city or other cities within Ethiopia thus, the retailer where the study took place would be a limitation to generalization.

\subsection{Delimitations}

The impacts of stock outs were explored in terms of customers physically going to traditional offline stores to shop for a specific brand or item and were viewed from customers' perspectives and possible changes in purchasing behaviors if the item(s) are not available. Merely Shewa Shopping Center were used as datacollection place.

\subsection{Significance of the Study}

The result of this study will enable companies using the lean inventory principles to pursue and discover mitigating practices to solve the stock-out problem and to provide customers with more satisfactory service. Results would help supply chain Shewa Shopping Center improve lean inventory practices and possibly reduce customer stock-out experiences. Showing the specific relationships between stock-out occurrences and customer satisfaction could enable Shewa Shopping Center to plan better inventory levels and alleviate the risks of lean inventory operations.

As Shewa Shopping Center holding fewer inventories on hand, manufacturers can produce only needed quantities, resulting in use of less raw material and energy to make goods. Applying best practices principles and increasing efficiency normally lead to a sustainable supply chain Pagell, (2009). Moreover, by operating more efficiently, Shewa Shopping Center can pass on savings to their customers and, subsequently, could improve the quality of life for customers with lower incomes.

The outcomes of this study will inform Shewa Shopping Center of specific problems associated with poor customer service caused by stockout and would enable retailers to provide better service to customers while keeping profit margins. By applying lean inventory, companies achieve monetary gain while exercising social responsibility. Senge et al. (2008) stated, the world's best companies recognize that for a supply chain to be robust and sustainable, all stakeholders in the chain must be leaders in minimizing environmental impact. Applying lean inventory creates a winning strategy for retail companies, as retailers can save money from not 
carrying unnecessary inventory, improve operational efficiency, and contribute to the long-term sustainability of the national environment.

\section{RESEARCH METHOD AND DESIGN}

The qualitative method is the most appropriate approach for this exploratory research, as the objective is to discover changes in customers' purchasing behaviors from experiencing stock-out. The qualitative method is suitable for this study because in qualitative inquiry, the researcher focuses on discovering the meaning that participants hold about the issue or problem and does not consider his or her own opinions (Creswell, 2009). The study tool used in this research is composed of 25 close ended and open-ended questions. The questions permitted participants to articulate how the stock-out experience affected their shopping behaviors during their shopping trip and how a stock-out situation might influence future purchasing campaigns.

\subsection{Method}

Barnham (2010) specified that the qualitative method enables analysis of consumers' attitudes and changes in perceptions following certain events. Eriksson and Kovalainen (2008) confirmed that the qualitative approach has been used in business research for long time. Sandelowski, Voils, and Knafl (2009) stated qualitative research studies are "generally considered to be qualitative modes of sampling, data collection and analysis and interpretation". The validity of the qualitative approach is maintained through accuracy of the findings and the use of disciplined process, while reliability is attained through consistency in the research approach (Gibbs, (2007). A pilot study was conducted to improve validity and ensure reliability of the study tool.

\subsection{Research Design}

According to Klopper (2008) "The research design is the plan or blueprint that the researcher will use in conducting the research". Creswell (2009) regarded the qualitative research approach as a venue in which "the researcher seeks to establish the meaning of a phenomenon from the views of participants". The study questionnaire is designed with questions that included close ended and open-ended questions to allow participants to express the full range of behavior and attitude changes of respondents. The study questions are designed to provide answers to the central research question and specific questions of this study.

\subsection{Population and Sampling}

The population for this research is drawn from customers buying at Shewa Shopping Center in Addis Ababa. The simple random sampling scheme was used to ensure authenticity of the sample, as everyone in the population have the same chance of selection without any bias Onwuegbuzie, \& Leech, (2007). Random study of every 10th person ensured every customer have the same possibility to be selected.

One hundred customers were asked to participate during the study periods. Asking every 10th customer to participate equated to studying a population of 1000. This sample size was considered large enough to explore the important perceptions and opinions and represent the full range of customers who frequently buy at Shewa Shopping Center.

This random sample reached data saturation level which were provide adequate representation of the social diversity of customers, and addressed the depth of this qualitative inquiry Onwuegbuzie, \& Leech, (2007). The eligibility criterion for participation was whether the customer experienced stock-out at any time during the preceding one week. Shoppers approached as they walked by the table set up conveniently near the exits of the Shopping Center. I approached target customers, made an introduction, and asked if they would be willing to participate in a short study. If the answer is 'yes,' the participant was asked if he or she had experienced stockout at a retail store during the past one week or in the Shopping Center that day. Those customers who answered 'no' were thanked, and no further action was taken. Customers who answered 'yes' to the stock-out question were offered a seat and they asked to complete the questionnaire.

\subsection{Data Collection Technique}

The data collection instrument was a self-designed study constructed of 25 questions of different styles and format, to allow participants to express the full range of behavior and attitude changes and answer the research central question and sub-questions. To ensure validity and avoid problems with ambiguity, the study was first validated through a pilot study with a group of ten academic colleagues to ensure there is no ambiguity, double meaning or misunderstandings in any of the listed questions. Rubio et al (2003) considered using 10 participants in a pilot study to be adequate to address clarity, phrasing, and other content issues. Answers from the pilot study were evaluated, and responses that improved clarity, format, and content were incorporated into the study. Then respondents were asked to write their responses on the questionnaire paper with pen to ensure their writing was permanent and could not be erased or altered by anyone after they had answered. 


\subsection{Data Organization Techniques}

The data was collected, coded, and analyzed for trends, themes, and changes in purchasing habits. Data coded into three major categories: customer product loyalty, store loyalty, and alleviating processes. Eriksson and Kovalainen (2008) considered coding and organization of the data are an essential part of qualitative research process. The information collected was analyzed for coherent results and presentation of findings and conclusions. The three major categories were explored include customers' behavioral changes in store and brand loyalty and potential alleviation.

\subsection{Data Analysis}

The study explored the qualitative effects of stock-out experiences on customers' loyalty and purchasing behaviors. The information collected was analyzed to determine the level of customer satisfaction and effects of stock-out on customers using retailers who practice lean inventory principles. The primary data was coded into three major categories: brand loyalty, store loyalty, and alleviating process. The data was further coded into subcategories that addressed general social characteristics such as employment, marital status, age, and gender. Collecting, analyzing, and interpreting the data was accomplished in a consistent and unbiased way. Entire responses were captured, including discourse and out of the norm answers, to ensure all responses are considered in the overall analysis. Creswell (2009) claimed qualitative analysis as "The process of data analysis involves making sense out of text and image data". Integrity of the data was maintained and presented correctly in the observations, conclusions, and recommendations.

\section{SUMMARY, CONCLUSION AND RECOMMENDATIONS}

\subsection{Summary}

The lean inventory concept has been shown to simplify operations and improve efficiency in a retail environment. The negative side of this is that low inventories increase the risk of stores' not having items the public has been accustomed to having. The stock-out problem is costly for retailers because it negatively affects brand and retailer loyalty. Shoppers who experience repeated stock-out experiences abandon their purchase and go to other retailers temporarily or even permanently. Repeated stock-out experience also negatively affect customer loyalty and cause large numbers of them to switch retailers temporarily or permanently. Retailers should view the first stock-out occurrence as a clear signal from shoppers for the need to mitigate or avoid future stock-outs to maintain customer loyalty. Respondents confirmed an existing qualitative relationship between stock-outs and customers shopping behaviors. After experiencing stock-outs $34 \%$ of participants indicated, they bought a substitute product, whereas $49 \%$ decided to wait and buy the stock-out item during their next shopping journey. Answers also indicated that $15 \%$ of customers decided to quit their purchase and go elsewhere to purchase the stock-out product.

\subsection{Conclusions}

Generally, women responded differently to stock-out experiences than did men and were more likely to shift retailers and have decreased brand loyalty after experiencing more than one stock-out. Findings of the study also indicated that women value pleasant shopping experiences and respond more negatively to stock-out, and are more likely to change stores when they think they are receiving bad customer service.

There are two options for retailers address the stock-out problems: reducing stock-out occurrences through better inventory management and improving customer service. The study underlined the continued significance of the stock-out problem and identified some actions retailers can take to alleviate the effects of the stock-out problem on shoppers.

\subsection{Recommendations}

\subsubsection{Recommendation to Shewa Shopping Center}

This study points out that customers perceive retailer's inventory management to be responsible for the stock-out problem and expect retailers to take right actions to alleviate the effects. Evaluation of the findings lead to the following recommendations:

1. Showa Shopping Center should review existing inventory-management process and ensure adequate inventory levels are on hand to accommodate customer demand.

2. During a stock-out situation, if the item is available through the store's inventory, Showa Shopping Center should offer to special order the item and have it delivered to a customer's residence free of handling and delivery charges.

3. At the time of a stock-out situation, Shewa Shopping Center need to make an effort to help customers find the stock-out item by researching and making phone calls on behalf of the customer.

4. Shewa Shopping Center need to make the stock-out issue personal, take the customer's contact information and call to let them know when the item becomes in stock. 
5. Shewa Shopping Center must be aware of the total cost of the stock-out problem and make every attempt to ensure customer stock-out experience does not risk loyalty to either brand or Shewa Shopping Center.

\subsubsection{Recommendations for Researchers}

Since this research focused on the traditional offline single retail store situations within a shopping center, further research including more retailers in Addis is useful to understand the shoppers' response for retailers and brand during out of stock situations. Learning the changes in purchasing behavior of shoppers after experiencing stock-out would also be useful to retailers and would complement the results of this study by providing retailers and stakeholders across the supply chain a more complete picture of the effects of stock-out. A complete understanding of the stock-out problem implications can be useful to the retail community and other supply chain stakeholders. A broad knowledge of the stock-out effects can provide full alleviating measures to accommodate customers and ensure pleasant shopping experiences.

\section{References}

Bardaki, C., Pramatari, K., \& Miliotis, P. (2007). Integrating demand forecasting with replenishment in a hightech retail chain. The Journal of Business Forecasting, 26(2),

Barnham, C. (2010). Qualis? The qualitative understanding of essence. International Journal of Market Research, $52,757-773$.

Blazenko, G. W., \& Vandezande, K. (2003). Corporate holding of finished goods inventories. Journal of Economics and Business, 55, 255-266.

Comez, N., \& Kiessling, T. (2012). Joint inventory and constant price decisions for a continuous review system. International Journal of Physical Distribution \& Logistics Management,

Creswell, J. W. (2009). Research design: Qualitative, quantitative, and mixed methods approaches (3rd ed.). Thousand Oaks, CA: Sage.

Eriksson, P., \& Kovalainen, A. (2008). Qualitative methods for business research. London, England: Sage.

Gibbs, G. R. (2007). Analyzing qualitative data. In U. Flick (Ed). The Sage qualitative research kit. London, England: Sage.

Goldsby, T. J., Griffis, S. E., \& Roath, A. S. (2006). Modeling lean, agile, and leagile supply chain strategies. Journal of Business Logistics, 27(1), 57-79.

Gruen, T. W., \& Corsten, D. (2007). A comprehensive guide to retail out-of-stock reduction in the fast-moving consumer goods industry. Procter and Gamble Company, Cincinnati, $\mathrm{OH}$.

Janssens, G. K., \& Ramaekers, K, M. (2011). A linear programming formulation for an inventory management decision problem with a service constraint.

Klopper, H. (2008). The qualitative research proposal. Curationis, 31(4), 62-72. Retrieved from http://www.curationis.org.za/index.php/curationis

Koumanakos, D. P. (2008). The effect of inventory management on firm performance. International Journal of Productivity and Performance Management, 57, 355- 369.

Lam, C. Y., \& Ip, W. H. (2011). A customer satisfaction inventory model for supply. Expert Systems with Applications, 38, 875-883.

McKinnon, A. C., Mendes, D. D., \& Nababteh, M. M. (2007). In-store logistics: International Journal of Logistics: Research \& Applications, 10, 251-268.

Musalem, E. P., \& Dekker, R. (2005). Controlling inventory in a supply chain: A case study. International Journal of Production Economics, 93, 179-188.

Nasr, W. W., Salameh, M. K., \& Moussawi-Haidar, L. (2012). Transshipment and safety stock under stochastic supply interruption in a production system. Computer \& Industrial Engineering, 63(1), 274-284.

Onwuegbuzie, A. J., \& Leech, N. L. (2007). A call for qualitative power analyses. Quality \& Quantity, 41, $105-$ 121.

Pagell, M., \& Wu, Z. (2009). Building a more complete theory of sustainable supply chain management. Journal of Supply Chain Management, 45(2), 37-56.

Rani, L., \& Velayudhan, S. K. (2008). Understanding consumer's attitude towards retail store in stockout situations. Asia Pacific Journal of Marketing and Logistics.

Rubio, D., Berg-Weger, M., Tebb, S., Lee, E., \& Rauch, S. (2003). Objectifying content validity: conducting a content validity study in social work research. Social Work

Sandelowski, M., Voils, C. I., \& Knafl, G. (2009). On quantitizing. Journal of Mixed Methods Research, 3, 208222.

Schottmiller, P. (2010). Why do you still have out-of-stock? A new approach to solving an old problem. Cisco Internet Business Solutions Group, (11/10), 1-4. Retrieved from http://www.cisco.comweb/about/ac79/docs/pov/Merchandising_Logistics.pdf

Senge, P., Smith, B., Kruschwitz, N., Laur, J., \& Schley, S. (2008). The necessary revolution: How individuals and organizations are working together to create a sustainable world. New York, NY: Doubleday. 
Svensson, G. (2000). A conceptual framework for the analysis of vulnerability in supply chains. International Journal of Physical Distribution \& Logistics Management, 30,

Vasconcellos, L. H. R., \& Sampaio, M. (2009). The stockouts study: An examination of the extent and the causes in the Sao Paulo supermarket sector. Brazilian Administration Review, 6(3), 263-279.

Verbeke, W., Farris, P., \& Turik, R. (1998). Consumer response to the preferred brand out-of-stock situation. European Journal of Marketing, 32, 1008-1028.

Yang, K., Ruben, R. A., \& Webster, S. (2003). Managing vendor inventory: A dual level distribution system. Journal of Business Logistics, 24(2), 91-108.

Zinn, W., \& Liu, P. C. (2008). A comparison of actual and intended consumer behavior in response to retail stock-outs. Journal of Business Logistics, 2(29), 141-159. 